\title{
Master-Slave Approach for a Multi-terminal VSC-HVDC Systems Connected Offshore Wind Farm
}

\author{
Mohamed amine Kazi ${ }^{l}$, Radouane Majdoul ${ }^{l}$, Nadia Machkour ${ }^{1}$, Adnane El-alami ${ }^{l}$, Ibrahim Baraka ${ }^{2}$ \\ ${ }^{1}$ Structural Engineering, Intelligent Systems \& Electrical Energy,University Hassan II, ENSAM, Casablanca \\ ${ }^{2}$ Advanced Science and Technology,University Abdelm alek Essaadi, ENSA, Tetouan
}

\begin{abstract}
The world is facing today the global challenge of energy transition since countries need more and more energy to grow their economy on a planet where resources are limited and poorly distributed. The integration of renewable energies and especially offshore wind energy into high voltage direct current (VSC-HVDC) transmission systems demonstrates great flexibility and reliability. In this paper, a control strategy for a multi-terminal VSC-HVDC system based on Master-Slave approach is proposed to automatically share the real power variation and stabilize the DC bus voltage in presence of abnormal operating conditions.
\end{abstract}




\section{Introduction}

Electricity needs are constantly growing, and infrastructure based on interconnected and interconnected transport networks is gradually coming to the limit of their capacity. The use of new means of production and the need to build infrastructure to transport this energy creates new opportunities.

Electricity is now produced, transported and distributed by electricity alternative (AC). This choice is due to a few major reasons: simplicity of production (generators are simpler and more reliable than direct current (DC) generators) as well as the ease of changing the voltage level using transformers. However, the control of alternating current energy transfers dense networks, increasingly difficult problems to solve such as: the distribution of energy transits in the various branches of mesh networks

is made according to physical laws and cannot be controlled easily, the reactive power must be compensated as close as possible to its consumption in order

limit voltage losses and drops, frequency settings of interconnected alternators must be coordinated.

Transmission of electrical energy using submarine cables is limited short distances in the case of HVAC due to the high dielectric capacity of the cables, and therefore, compensating shunt reactances are necessary to limit the effective transmission distance. Direct interconnection of asynchronous AC networks is not possible via HVAC links [1-3]

These restrictions necessitated the search for alternative solutions, which, together with the technological developments and advances in power electronics have made it possible to advance in the transmission of electric power. As a result, HVDC transmission systems emerged. As a result, economic and technological actions to reinvigorate the energy market were provided. Cheaper and more efficient interconnections have been achieved. In addition, HVDC transmission systems have made it easy to interconnect networks where voltage and frequency are not compatible or when there are geographical obstacles such as seas, or oceans, or mountains

Renewable energy [4] is constantly innovating in the new global market. Although renewable electricity generating plants are often far from consumption points, the energy transmission with minimal losses must be In the case of renewable offshore wind generation sources, it is necessary to transmit large quantities of energy with satisfactory efficiency. To this end, several projects using
HVDC technologies in combination with renewable energies are being developed in particular via cables submarines.

For environmental, technical and economic reasons, the installation of HVDC lines is promoted in order to maximize the efficiency of electricity transmission. As a result, the last five decades have witnessed a significant development of HVDC transmission systems. The HVDC technology has been developed to: Interconnect remote areas to facilitate energy exchanges, Connect offshore wind farms, deliver hydroelectric power...

In this context we have carried out this work which addresses the problem of MTDC multi-terminal HVDC systems [5-8], our MTDC system consisting of 3 terminals as shown in Figure 1 each conversion station is coupled with the AC network through equivalent impedance, same for Station 2 which is connected to an offshore wind farm. For the DC part all the conversion stations are interconnected via transport cables. The first part of this paper will be devoted to the modeling of the wind turbine and the VSC conversion system, then the second part to the Master-Slave control based on PI Controller and finally a simulation and discussion of the results.

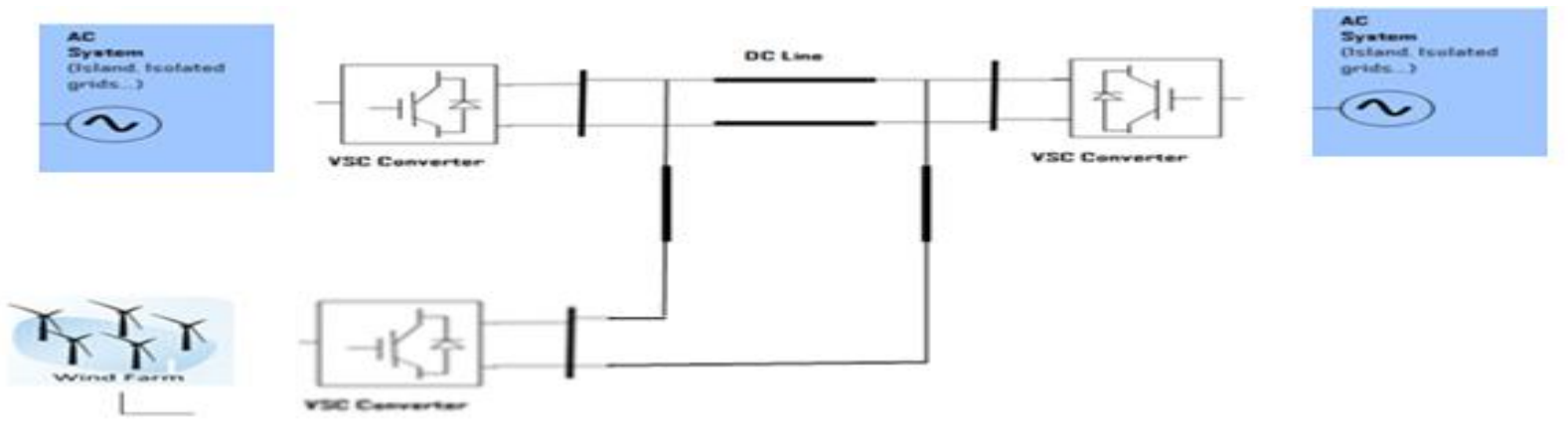

Fig.1. Model for the VSC-HVDC system. 


\section{Mathematic Model of VSC-HVDC System}

\subsection{Wind Turbine}

The mechanical power output of the wind turbine (WT) is

$$
P_{M}=\frac{1}{2} \cdot \rho \cdot A \cdot V^{3} \cdot C_{P}(\theta, \lambda)
$$

Where:

$\rho:$ is the air density $\left[\mathrm{kg} / \mathrm{m}^{3}\right]$

$A$ is the swept area of the rotor in $m^{2}$,

$V$ is wind speed in $\mathrm{m} / \mathrm{s}$,

$C_{P}$ is the power coefficient which is a function of both tip speed ratio $\theta$ and blade pitch angle $\lambda[\mathrm{deg}] . C_{P}$ is expressed in the next equations

$$
\begin{gathered}
C_{P}=0,73\left(\frac{151}{\lambda_{k}}-0,58 \cdot \theta-0,002 \cdot \theta^{2,14}-13,2\right) \cdot e^{\frac{-18,4}{\lambda_{k}}} \\
\frac{1}{\lambda_{k}}=\frac{1}{\lambda-0,02 \cdot \theta}-\frac{0,003}{\theta^{3}+1} \\
\lambda=\frac{\omega_{r} \cdot R}{V}
\end{gathered}
$$

Where $\lambda$ the tip speed ratio and $\omega_{r}$ the rotor rotational speed in $\mathrm{rad} / \mathrm{sec}, \mathrm{R}$ is the radius of the wind turbine in $\mathrm{m}$

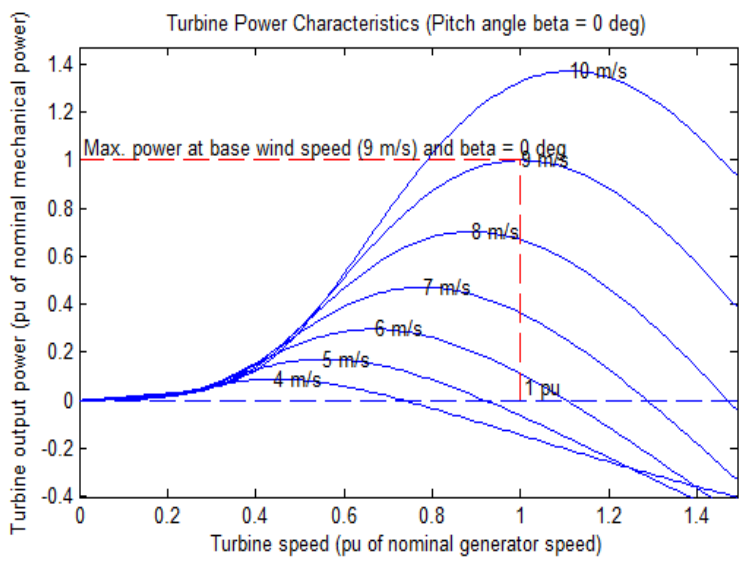

Fig 2. Turbine Output Power

\subsection{Voltage source converters (VSC)}

The converter is the main element of the operation it is connected to an $\mathrm{AC}$ network through an impedance line; the DC bus voltage is filtered by a capacitor $\mathrm{C}$. The VSC converter shown in Fig.3

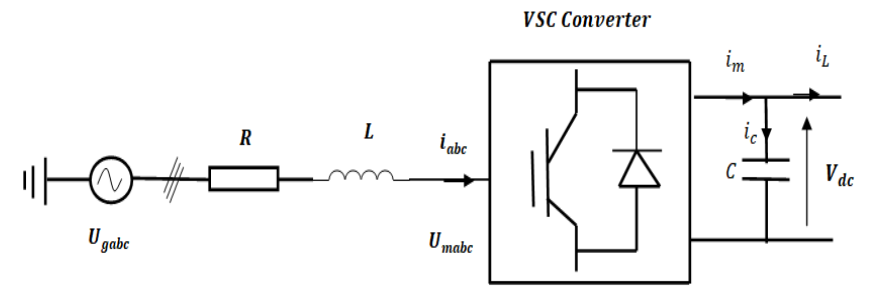

Fig.3. Structure of VSC Converter

Apply Kirchhoff's voltage law we find

$$
\text { L. } \frac{\mathrm{di}_{\mathrm{j}}}{\mathrm{dt}}+\mathrm{R} \cdot \mathrm{i}_{\mathrm{j}}=\mathrm{u}_{\mathrm{gj}}-\mathrm{u}_{\mathrm{mj}}
$$

The system (1) can be written as:

$$
\mathrm{u}_{\mathrm{mabc}}=-\mathrm{R} \cdot \mathrm{i}_{\mathrm{abc}}-\mathrm{L} \cdot \frac{\mathrm{di}}{\mathrm{dt}}+\mathrm{u}_{\mathrm{gabc}}
$$

Equation (2) is then written in the Park transform:

$u_{\text {mdq } 0}=-R \cdot i_{d q 0}-L \cdot P(\theta) \cdot \frac{d_{a b c}}{d t}+u_{g d q 0}$

By neglecting the transformation losses at the converter, the active power exchange on the AC source side will be equal to the power at the DC bus, and then we have:

$$
\mathrm{P}_{\mathrm{gdq}}=\mathrm{P}_{\mathrm{DC}}
$$

However, the active and reactive powers from the source are expressed respectively by the equations:

$\mathrm{P}_{\mathrm{gdq}}=\frac{3}{2} \cdot\left(\mathrm{u}_{\mathrm{gd}} \cdot \mathrm{i}_{\mathrm{d}}+\mathrm{u}_{\mathrm{gq}} \cdot \mathrm{i}_{\mathrm{q}}\right)=\frac{3}{2} \cdot\left(\mathrm{u}_{\mathrm{gq}} \cdot \mathrm{i}_{\mathrm{q}}\right)$

$\mathrm{Q}_{\mathrm{gdq}}=\frac{3}{2} \cdot\left(\mathrm{u}_{\mathrm{gq}} \cdot \mathrm{i}_{\mathrm{d}}-\mathrm{u}_{\mathrm{gd}} \cdot \mathrm{i}_{\mathrm{q}}\right)=\frac{3}{2} \cdot\left(\mathrm{u}_{\mathrm{gq}} \cdot \mathrm{i}_{\mathrm{d}}\right)$

\section{Control strategies for MTDC systems}

MTDC transmission systems are used to connect offshore power sources and wind farms to electrical grids. They provide flexible, fast, and reversible control of power flow. However, the operation and control of an MTDC system is still an open and challenging problem.

Several research works have proposed different control structures to ensure the normal operation of an MTDC system [9-13]. A control strategy called "Master-Slave" is applied to MTDC networks based on VSC converters [1416]. It consists in considering a terminal as a "master" station to control the DC bus voltage at the desired value, while the other terminals are called "slave" stations, they are reserved for the "slave" stations.

The other terminals are called "slave" stations; they are reserved for the control of power flows and other variables. 


\subsection{Inner Current Controller}

The internal control loop provides control of the $i_{a b c}$ current through the AC filter. This control structure allows the direct and quadrature currents to be decoupled and controlled independently. The dynamics of the currents can be adjusted using the properties of properties of second order polynomials

\subsection{Outer Controllers}

\subsubsection{DC voltage control}

The DC voltage control loop is required to control the DC bus voltage by ensuring the balance between the power injected to the DC network and the power absorbed by the AC network. The structure of the controlled system is illustrated below. The output of the control loop provides the reference input of the forward current. The PI controller is widely used in HVDC applications to control the DC voltage at a constant level, and the integral action allows for zero steady state error.

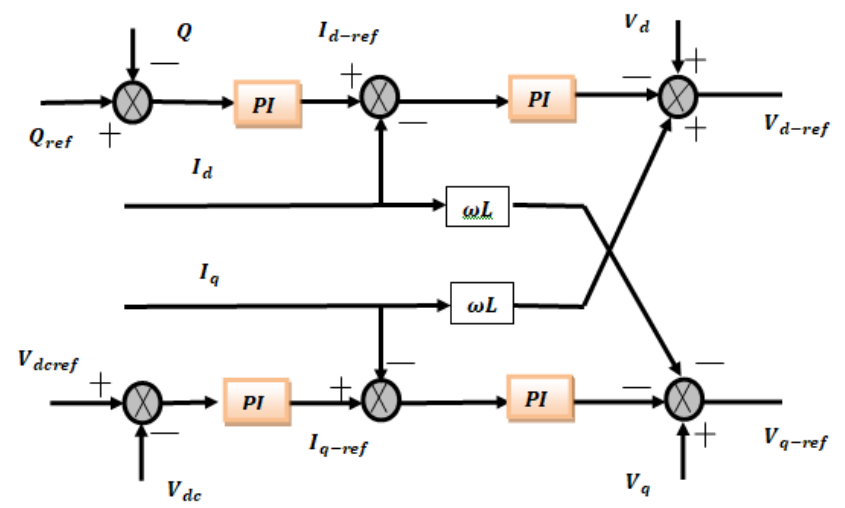

\subsubsection{Real power control}

Active and reactive power can be controlled independently. They are used to generate the reference currents of the internal loops. Bloc diagram below shows the structure of the power control loops. PI correctors are used to regulate the dynamic responses of the power loops.

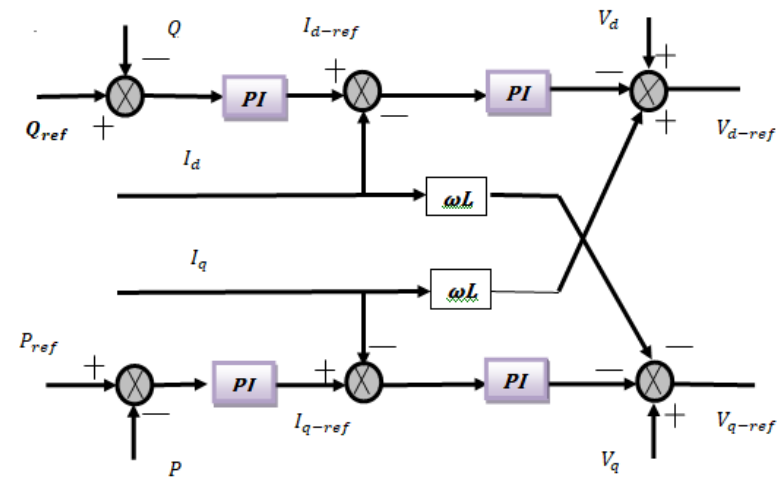

Fig. 4 shows the bloc diagram of the proposed control based on Master-Slave approach which the outer loop control the DC bus voltage or active power. In our paper we propose that station 2 is considered as Master and station 1 and the wind farm are considered as slaves, so the outer loop will depend on the control type (Mode DC Control or Mode Power Control)

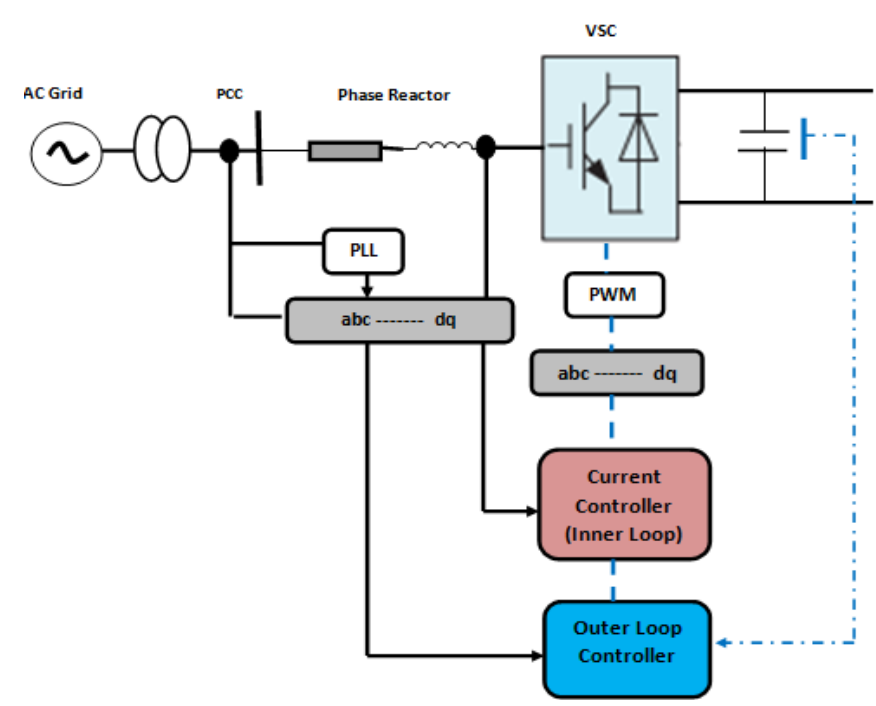

Fig. 4. Schematic diagram of control

\section{Simulation Analysis and Results}

To illustrate the validity of the linear control proposed for the control of a multi-terminal HVDC transport network based on a VSC conversion system, a simulation study was carried out using Matlab/Simulink. The 3terminal VSC-MTDC based offshore wind farm and onshore AC system is shown in Fig. 5

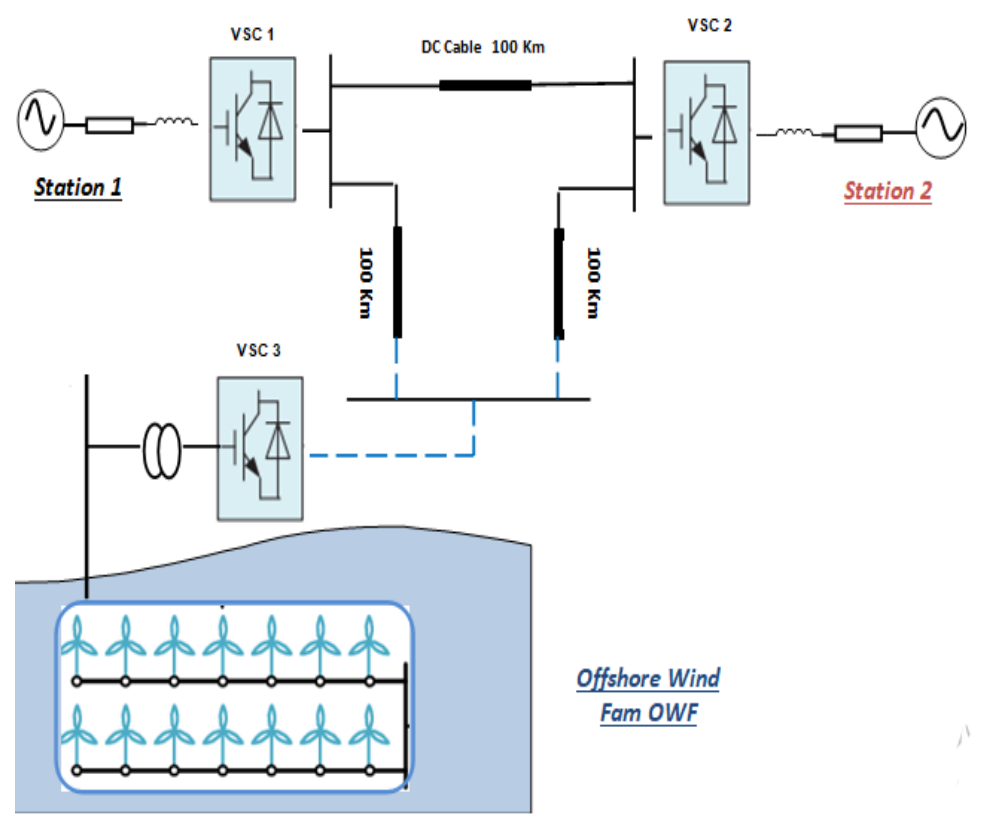

Fig. 5. Structure of 3-terminal VSC-HVDC 
Table 1 presents the simulation parameters of the studied system:

Table. 1. Parameters of System

\begin{tabular}{|l|l|}
\hline Quantity & Value \\
\hline AC grid voltage & $230 \mathrm{kV}$ \\
\hline Grid resistance & $900 \mathrm{~m} \Omega$ \\
\hline Grid inductance & $62.23 \mathrm{mH}$ \\
\hline Input voltage source (wind turbine) & $250 \mathrm{kva} 400 \mathrm{~V}$ \\
\hline Base power & $1000 \mathrm{MVA}$ \\
\hline Nominal DC voltage & $200 \mathrm{kV}$ \\
\hline Nominal frequency & $50 \mathrm{~Hz}$ \\
\hline DC capacitor & $35 \mu \mathrm{F}$ \\
\hline DC cable resistance & $13,9 \mathrm{~m} \Omega / \mathrm{km}$ \\
\hline DC cable inductance & $0,159 \mathrm{mH} / \mathrm{km}$ \\
\hline DC cable capacitance & $0,231 \mu \mathrm{F} / \mathrm{km}$ \\
\hline Rated wind speed & $11 \mathrm{~m} / \mathrm{s}$ \\
\hline
\end{tabular}

To test the performance of the system and to see its capacity to adapt with the variations of the operating conditions we have proposed two scenarios:

\section{A- Power fluctuation}

We consider the case of a power operating point change described as follows:

At $\mathrm{t}=1.5 \mathrm{~s}$ a variation of the reference power input of station1 from 1.0 p.u to 0.7 p.u.

The dynamic evolution in voltage and power as a result of the applied event is illustrated in Fig. 6 to Fig11.

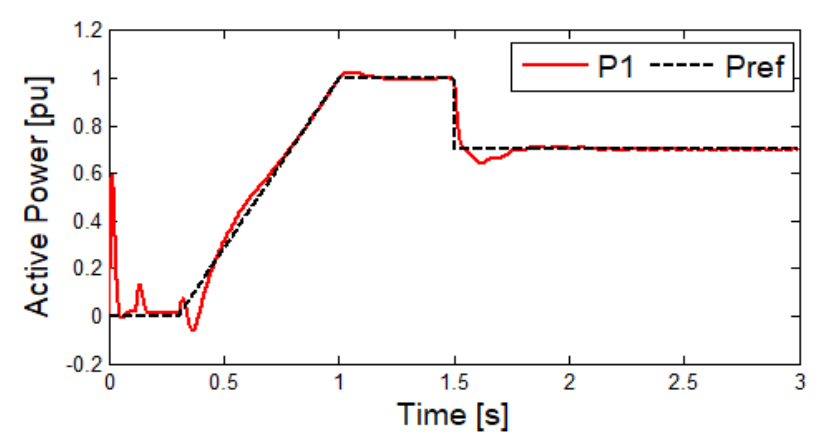

Fig.6. Active Power in Station 1

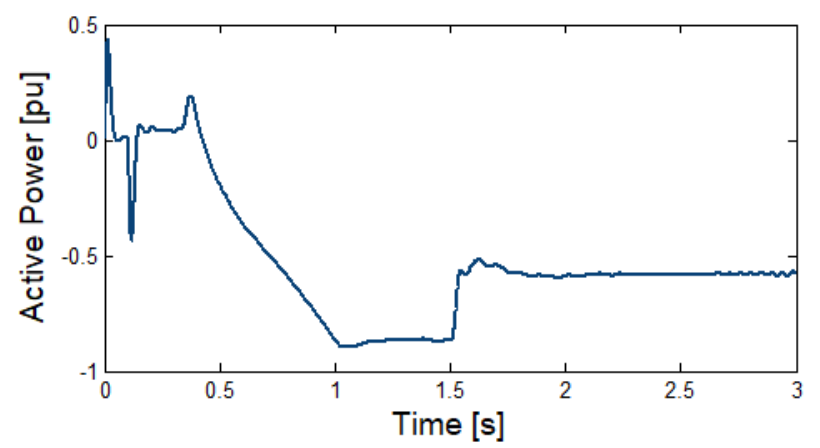

Fig.7. Active Power in Station 2

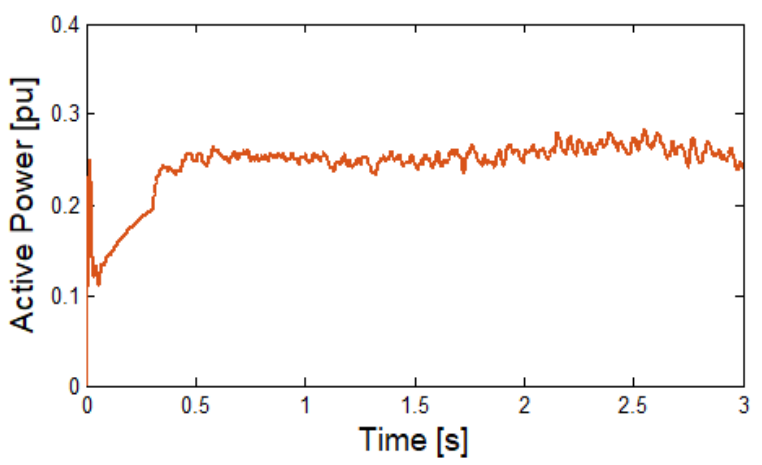

Fig.8. Active Power in Wind Farm

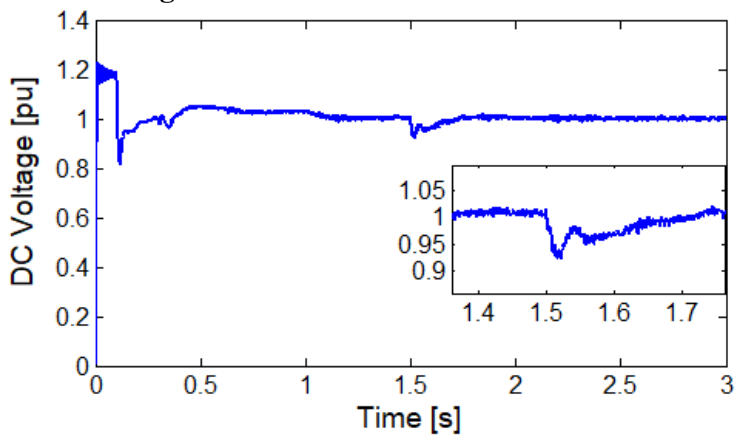

Fig.9. DC Voltage in Station 1

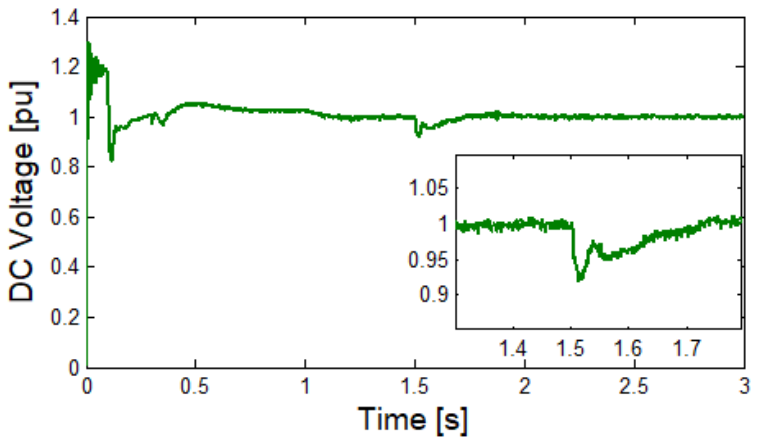

Fig.10. DC Voltage in Station 2

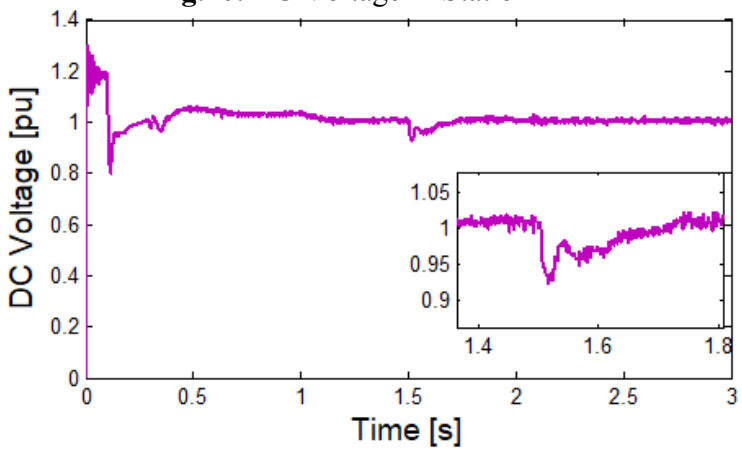

Fig.11. DC Voltage in Wind Farm

\section{B- Three phase fault at an AC grid (Master)}

In order to simulate a fault on the AC line, we produced a phase break between the instants $t=1 \mathrm{~s}$ and $\mathrm{t}=1$.1s of the AC grid of station 2 (Master) the figures below show the behavior 


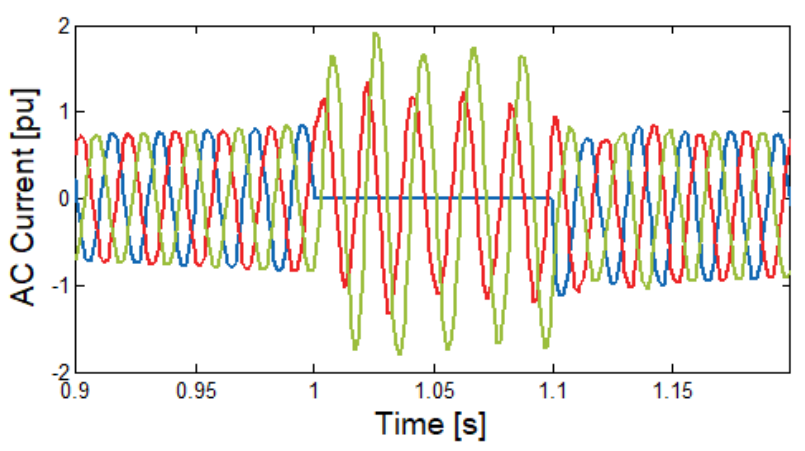

Fig.12. AC Current in Station 2

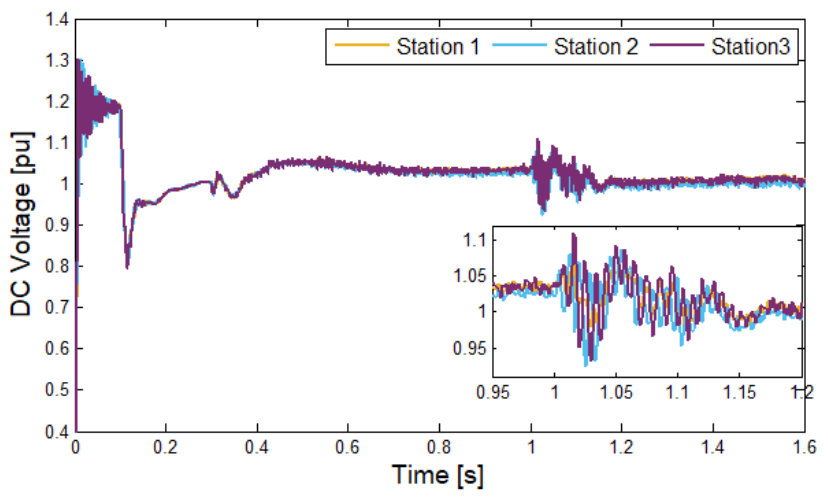

Fig.14. DC Voltage in all Stations

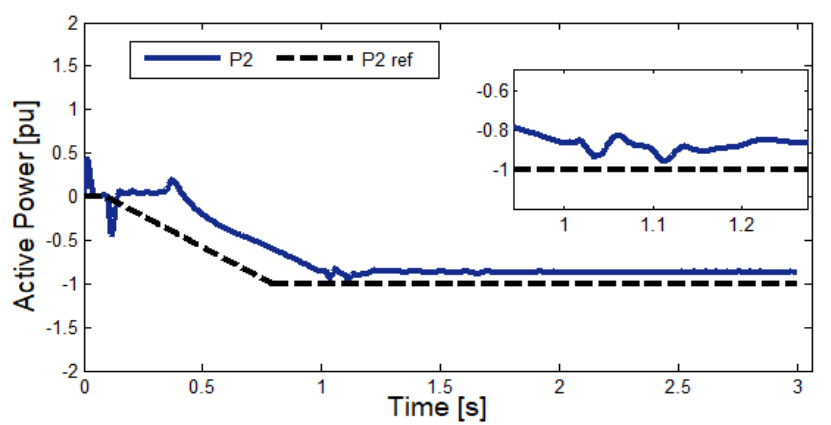

Fig. 16.. Active Power Station 2

Despite the fact that it is a linear PI control, we can see that the results are quite satisfactory. The VSC-HVDC multi-terminal system is tested with two types of faults, the first one deals with the problem of power variation which is a frequent phenomenon on the electrical networks, according to the results found the active power variation at station 1 leads to a deficit in this case we notice that the other stations have to compensate this lack as we see at the level of station 2 which allows to re-inject active power and also let us notice that the voltages of the DC bus come back towards their reference values, The second fault is a break in the AC line which occurs on phase 1 and destabilizes the system during this period, here the Master must resume its normal operation since we notice that after a short time the DC bus voltages and power flows return to their reference values with an acceptable dynamic response.

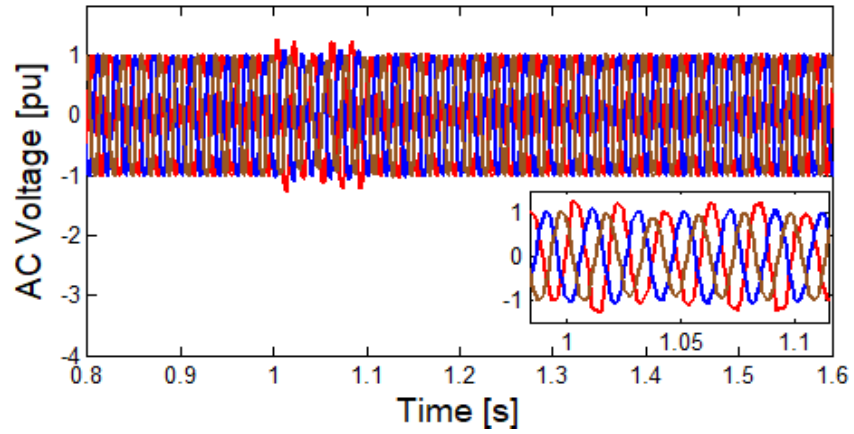

Fig.13. AC voltage in Station 2

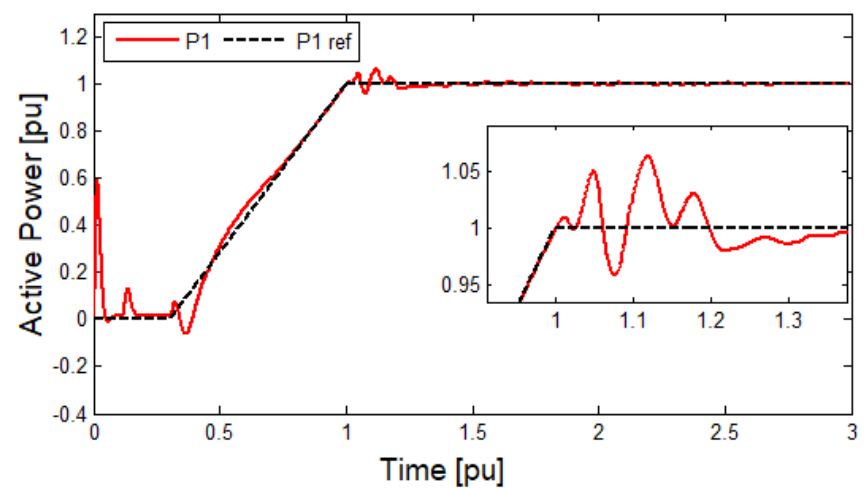

Fig.15. Active Power Station 1

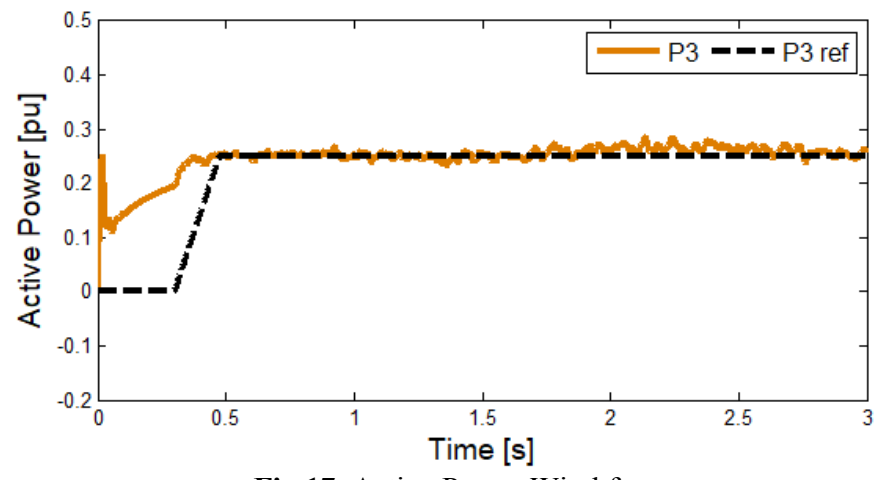

Fig.17. Active Power Wind farm

Limiters should be placed on each inverter to allow the deviation to be adjusted to a maximum acceptable power. These deviations, on the other hand, must be chosen to ensure the correct operation of each converter as well as the overall system.

\section{Conclusion}

Large-scale DC grids are an important issue in the coming years as this infrastructure will allow connecting offshore renewable generation with the rest of the grid. In this paper, we have presented the study and control of multi-terminal HVDC MTDC systems based on the Master-Slave technique. Through the simulation results obtained, we observe respectable system performances and a convergence towards the reference values during injected faults, However, this control has some drawbacks such as the dynamic response of the system that can generate more oscillations and the possibility of failure or 
loss of a terminal, note that this topic can be further developed through more robust and optimal controls that we plan to continue our work.

\section{References}

[1] C.Bayliss, B.Hardy. Transmission and Distribution electrical engineering. Elsevier, 2007

[2] K. Meah and S. Ula, "Comparative evaluation of HVDC and HVAC transmission systems," In IEEE Power Engineering Society General Meeting, pages 1-5, 2007.

[3] J. Dorn, H. Gambach, D. Retzmann, "HVDC Transmission Technology for Sustainable Power Supply, " in 2012 International MultiConference on Systems, Signals \& Devices, (2012)

[4] Gross, R., Leach, M,. Bauen, A. - Progress in renewable energy,Environment International, vol. 29, No. 1, pp. 105-122, Avril 2003

[5] Asma Rekik, Ghada Boukettaya, Randa Kallel, "Comparative study of two control strategies of a Multiterminal VSC-HVDC systems," Proceedings of 7th International Conference on Systems and Control (ICSC) 2018

[6] Jun Liang, Oriol Gomis-Bellmunt, Janaka Ekanayake, Nicholas Jenkins, Wen An, A multiterminal HVDC transmission system for offshore wind farms with induction generators in Electrical Power and Energy Systems 43 (2012) 54-62

[7] M. Ajay Kumar, N.V. Srikanth, An Adaptive Coordinated Control for an Offshore Wind Farm Connected VSC Based Multi-Terminal DC Transmission System, Open Eng. 2015; 5:6-17

[8] Mohamed AYARI, Approches d'analyse et de commande non linéaire de systèmes de transmission HVDC (2017)

[9] Guo-Jie Li, Si-Ye Ruan, Tek Tjing Lie, Real power regulation design for multi-terminal VSCHVDC systems, Cent. Eur. J. Eng. • 3(2) • 2013 -243-252

[10] Cheng Lv, Nengling Tai, Control for offshore wind power integration based on modular multilevel converter, 6th International Conference on Renewable Power Generation (RPG) 19-20 October 2017

[11] Samy Akkari, Control of a multi-terminal HVDC (MTDC) system and study of the interactions between the MTDC and the AC grids, 13 Oct 2016

[12] Xudan Liu, Andreas Lindemann, Control of VSC-HVDC Connected Offshore Windfarms for Providing Synthetic Inertia, EEE Journal of Emerging and Selected Topics in Power Electronics (2017).

[13] Weiwei Zou, Haiying Dong, Xiaojing Chen , Kaiqi Liu, Small Signal Modeling and Decoupling Control of VSC-MTDC, 2020 Chinese Control And Decision Conference (CCDC) (2020)
[14] Wenjuan Du;Qiang Fu;Haifeng Wang, Comparing AC Dynamic Transients Propagated Through VSC HVDC Connection With MasterSlave Control Versus DC Voltage Droop Control, IEEE Transactions on Sustainable Energy (2018)

[15] Hadi Alyami, Master-Slave with Droop Control for MTDC Grids, 2nd IEEE International Conference on Industrial Electronics for Sustainable Energy Systems (IESES) (2020)

[16] B A Giwa, O Olowookere;S Skarvelis-Kazakos, Small scale multi-terminal HVDC transmission test rig, 7th IET International Conference on Power Electronics, Machines and Drives (PEMD 2014) 